\title{
Enterprise Coherence in the Dutch Ministry of Social Affairs and Employment ${ }^{\star}$
}

\author{
Roel Wagter ${ }^{1,3}$, H.A. (Erik) Proper ${ }^{2,3}$, and Dirk Witte ${ }^{4}$ \\ 1 Ordina, Nieuwegein, The Netherlands \\ 2 PRC Henri Tudor, Luxembourg \\ 3 Radboud University Nijmegen, Nijmegen, The Netherlands \\ 4 Logica, Amstelveen, The Netherlands \\ roel.wagter@ordina.nl, erik.proper@tudor.lu, \\ dirk.wittealogica.com
}

\begin{abstract}
This paper is concerned with a real world case study in Business/IT alignment at the strategic level. The case study is situated in the Dutch public sector, involving the Ministry of Social Affairs and Employment (SAE). In this case study, the GEA (Generic Enterprise Architecting) method was used. This paper will therefore take the GEA method as a given. Nevertheless, to better understand and appreciate the case study, we will also briefly review the GEA method and its background. Even more, we will also provide an evaluation on the GEA method, which was/is developed using a design science approach.
\end{abstract}

Keywords: business-IT alignment, enterprise coherence, enterprise architecture.

\section{Introduction}

This paper is concerned with a real world case in Business/IT alignment at the strategic level. The case is situated in the Dutch public sector, involving the Ministry of Social Affairs and Employment (SAE). It concerns the introduction of a new system for the creation of a digital document/dossier flow. The introduction of this system was a direct consequence of a government decision to automate these document processes by 2015 . It was decided by the Ministry to re-use the system that was already designed, and built, to support similar processes at another Ministry (the Ministry Internal Affairs and Kingdom Relationships). Therefore, the focus of the case is not so much on the creation of a new solution, but rather on the impact on the existing organization when using an existing solution. The specific business issues addressed in the case are: (1) What are the necessary change initiatives needed for the introduction of this new system? (2) What are the best choices in terms of solution direction and approach?

In the case study, the GEA (Generic Enterprise Architecting) method was used. Given the focus of this paper on the actual case study, we take the GEA method as a given. Nevertheless, to better understand and appreciate the case study, we will also briefly review the GEA method and its background.

\footnotetext{
* This work has been partially sponsored by the Fonds National de la Recherche Luxembourg (www. fnr. lu), via the PEARL programme.
} 
The remainder of this paper is structured as follows. In Section 2, we provide more background to the GEA method. Section 3 , then continues by summarizing that part of the GEA method that is most relevant to understanding the case study: the Enterprise Coherence Framework (ECF), which enables enterprise to set up their own coherence dashboard in terms of which the enterprise coherence can be governed/improved during enterprise transformations. The SAE specific configuration of this dashboard is discussed in Section 4 This is followed in Section 5, by a discussion on how this dashboard was used in a workshop to tackle the business issue at hand. Before concluding, Section 6 then briefly discusses an evaluation by the participants of the case.

\section{Background to the GEA Method}

The development of the GEA (General Enterprise Architecting) method was initiated in 2006 by the consultancy firm Ordina (www. ordina.n1). The decision by Ordina to initiate the development of the GEA method originated from the observation that large scale enterprise transformations fail more often than not, while, in their experience, existing methods and frameworks for enterprise architecture failed to contribute to the success of enterprise transformation efforts [6, 5]. A survey held at the start of the GEA programme, showed that this experience was not limited to Ordina only, but was shared among a broad range of client organizations participating in the programme 1 . The underlying issues were also considered grave enough for the participating client organizations to indeed co-invest, in terms of time and money, in the GEA programme. In the (still ongoing) development of GEA, the design science method [3] is used as the overarching "rhythm", combined with case study research [7] to evaluate the application of the different iterations of the GEA method.

In its current form, the GEA method comprises three core ingredients [5]. Next to the Enterprise Coherence Assessment (ECA) that allows organizations to assess their ability to govern coherence during enterprise transformation, it contains an Enterprise Coherence Framework (ECF) and a (situational) Enterprise Coherence Governance (ECG) approach. The latter includes the identification of specific deliverables to produced/results, processes needed to produce these deliverables/results, as well as an articulation of the responsibilities and competences of the people involved. The ECF, which will be summarized in the next section, enables enterprise to set up their own coherence dashboard in terms of the enterprise coherence can be governed/improved during enterprise transformations. This, enterprise specific, dashboard enables senior management to govern the coherence between key aspects of an enterprise during a transformations.

\footnotetext{
${ }^{1}$ During different stages of the GEA research programme, the following client organizations were involved: ABN AMRO; ANWB; Achmea; Belastingdienst - Centrum voor ICT; ICTU; ING; Kappa Holding; Ministerie van Binnenlandse Zaken en Koninkrijksrelaties; Ministerie van Defensie; Ministerie van Justitie - Dienst Justitiële Inrichtingen; Ministerie van LNV - Dienst Regelingen; Ministerie van Landbouw, Natuur en Voedselkwaliteit; Nederlandse Spoorwegen; PGGM; Politie Nederland; Prorail; Provincie Flevoland; Rabobank; Rijkswaterstaat; UWV; Wehkamp (see also WwW.groeiplatformgea.nl).
} 


\section{The Enterprise Coherence Framework}

The Enterprise Coherence Framework (ECF, see [5]) defines a series of cohesive elements and cohesive relationships, which together define the playing field for an enterprise's coherence. By making the definition of these elements explicit in a specific enterprise, a coherence dashboard results in terms of which one can gain insight in the 'state of coherence' while also being able to assess the impact of potential/ongoing transformations. This then enables a deliberate governance of enterprise coherence during/driving transformations.

The ECF is defined in terms of two connected levels of cohesive elements: the level of purpose and the level of design. At the level of purpose, the cohesive elements that have been identified, correspond to the commonly known concepts from strategy formulation [4, 1]: Mission, Vision, Core Values, Goals and Strategy. The cohesive elements at the design level are:

Perspective - an angle from which one wishes to govern/steer/influence enterprise transformations. The set of perspectives used in a specific enterprise depend very much on its formal and informal power structures. Both internally, and externally. Typical examples are culture, customer, products/services, business processes, information provision, finance, value chain, corporate governance, etc.

Core concept - a concept, within a perspective, that plays a key role in governing the organization from that perspective. Examples of core concepts within the perspective Finance are, for instance, "Financing" and "Budgeting".

Guiding statement - an internally agreed and published statement, which directs desirable behaviour. They only have to express a desire and/or give direction. Guiding statements may therefore cover policy statements, (normative) principles [2] and objectives.

Core model - a high level view of a perspective, based on, and in line with, the guiding statements of the corresponding perspective.

Relevant relationship - a description of the connection between two guiding statements of different perspectives.

The presence of a well documented enterprise mission, vision, core values, goals and strategy are preconditions to be able to determine the content of the core factors on the design level of the organization.

\section{The Coherence Dashboard for the Ministry of SAE}

Since this was the first time for the Ministry of SAE to apply/use the GEA method, it was necessary to first develop an organization specific coherence dashboard. To this end, the case at the Ministry of SAE started in August 2010 with an intensive desk research activity, conducted by a small team of architects. This team studied relevant policy documents from the Ministry of SAE, resulting in the first version of the coherence dashboard for the Ministry, in terms of a list of the cohesive elements and their definitions, covering both the purpose and the design level. Starting point for creating this list were the strategic documents of the organization such as the mission statement, vision notes, policy plans, business strategy, business plan, etc. 
In a validation workshop, conducted in September 2010, this draft coherence dashboard was then validated with the major stakeholders and approved after some modifications. This validation workshop involved the executives of the Ministry, complemented with a number of (internal) opinion leaders and key stakeholders.

Table 1. Definitions of perspectives for the Ministry of SAE

\begin{tabular}{|l|l|}
\hline Perspective & Definition \\
\hline $\begin{array}{l}\text { Information } \\
\text { provisioning }\end{array}$ & $\begin{array}{l}\text { All processes, activities, people and resources for obtaining, processing and delivery of relevant infor- } \\
\text { mation for SAE. }\end{array}$ \\
\hline Collaboration & Collaboration needed to contribute to a common result on the team, entity or organization levels. \\
\hline Processes & A coherent set of activities needed to deliver results of SAE. \\
\hline Governance & The influencing of the SAE organization so that a desired goal is attained. \\
\hline Employees & All persons who execute tasks or activities within the SAE organization. \\
\hline Stakeholders & Legal entities or persons for whom the activities of SAE are important. \\
\hline Culture & Explicit and implicit norms, values and behaviour within the SAE organization. \\
\hline Services & $\begin{array}{l}\text { All services that SAE within legal frameworks, or through agreed appointments with statutory author- } \\
\text { ities, establishes and delivers to customers. }\end{array}$ \\
\hline Finance & The planning, acquisition, management and accountability of funds SAE. \\
\hline Customers & Customers of a service of SAE \\
\hline Law \& regulations & All legal frameworks that form the basis for the task performance of SAE. \\
\hline Communication & $\begin{array}{l}\text { An active process in which information is exchanged between two or more parties or persons, regard- } \\
\text { less of how that is achieved. }\end{array}$ \\
\hline
\end{tabular}

In Table 1, the perspectives that were selected by the Ministry of SAE are shown, while the core concepts of four of the perspectives are listed in Table 2. This set of perspectives also illustrates the need to align more aspects of an enterprise rather than just business and IT. Several of the perspectives may put requirements towards IT support, information provisioning followed by communication being the dominant ones in this sense. However, the chosen set of perspectives shows that when it comes to alignment, the stakeholders do not think in terms of Business/IT alignment, but rather in a more refined web of aspects that need alignment.

Table 2. Core concepts for the Ministry of SAE

\begin{tabular}{|l|l|l|l|}
\hline Information provision & Processes & Governance & Stakeholders \\
\hline \hline Digitization & Time and place independent & Policy cores & Labor market \\
Integrality & Selection policy & Programs & Municipalities \\
Security & Efficiency & Scaling up & Labor force \\
Standardization & Actor & Collectivity & Employers Unions \\
Facilities & Effectiveness & Mission/vision assessment & Employee Unions \\
Information & Predictability & Employer ship & Funds \\
Maintenance & Planned & Themes and tasks & Other Ministries \\
Systems & Procedures & Functioning & Independent administrative bodies \\
Ownership & & Organization & Society \\
Storage & & & Social and Economic Council \\
Architecture & & & Research agencies \\
& & & Social partners \\
& & National Archive \\
\hline
\end{tabular}


Table 3. Guiding statements relevant to the processes perspective

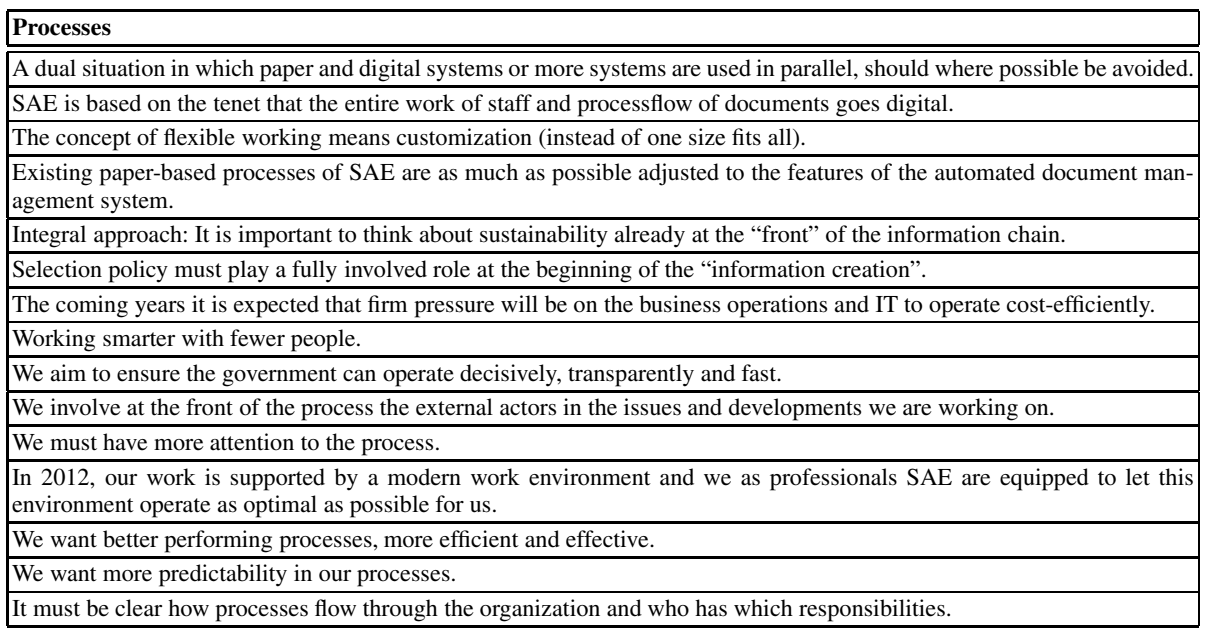

During the desk research phase 219 guiding statements were derived from the aforementioned policy documents. Needless to say that presenting all 219 guiding statements goes beyond the purpose of this paper. Therefore, Table 3 only shows those guiding statements that turned out to be relevant to the processes perspective.

\section{The Process Followed in the Case Study}

With the dashboard in place, the next step was to organize a workshop with the key stakeholders. In this workshop, the business issue at hand (the introduction of a new system for the digitization of the flow of dossiers) was positioned in relation to the coherence dashboard of the Ministry of SAE, and analysed in terms of the two questions: (1) What are the necessary change initiatives needed for the introduction of this new system? and (2) What are the best choices in terms of solution direction and approach?

During the workshop, each of the twelve perspectives of Table 1 was represented by one or two participants who had (delegated) ownership of that perspective. At the start of the workshop, the owner of the business issue gave a thorough introduction of the issue in terms of causes, degree of urgency, degree of interest, implications, risks, etc. See Table 4 (these lists were also handed out to the participants, before the workshop took place). This introduction gave the representatives of the perspectives a deeper insight into the associated aspects of this business issue, enabling them to make a translation of the issue to their own perspective. This enabled the representatives of the different perspectives jointly determine, which change initiatives were required to solve the business issue at hand. The business issue: "impact of the implementation of a digitization solution" was then addressed in terms of two tasks: (1) Determine the necessary change initiatives based on the analysis of the business issue and (2) Determine the necessary change initiatives based on the solution space dictated by the guiding statements of the coherence dashboard of the Ministry (such as for example shown in Table 3). 
Table 4. Part of the analysis of the business issue in terms of causes, implications and risks

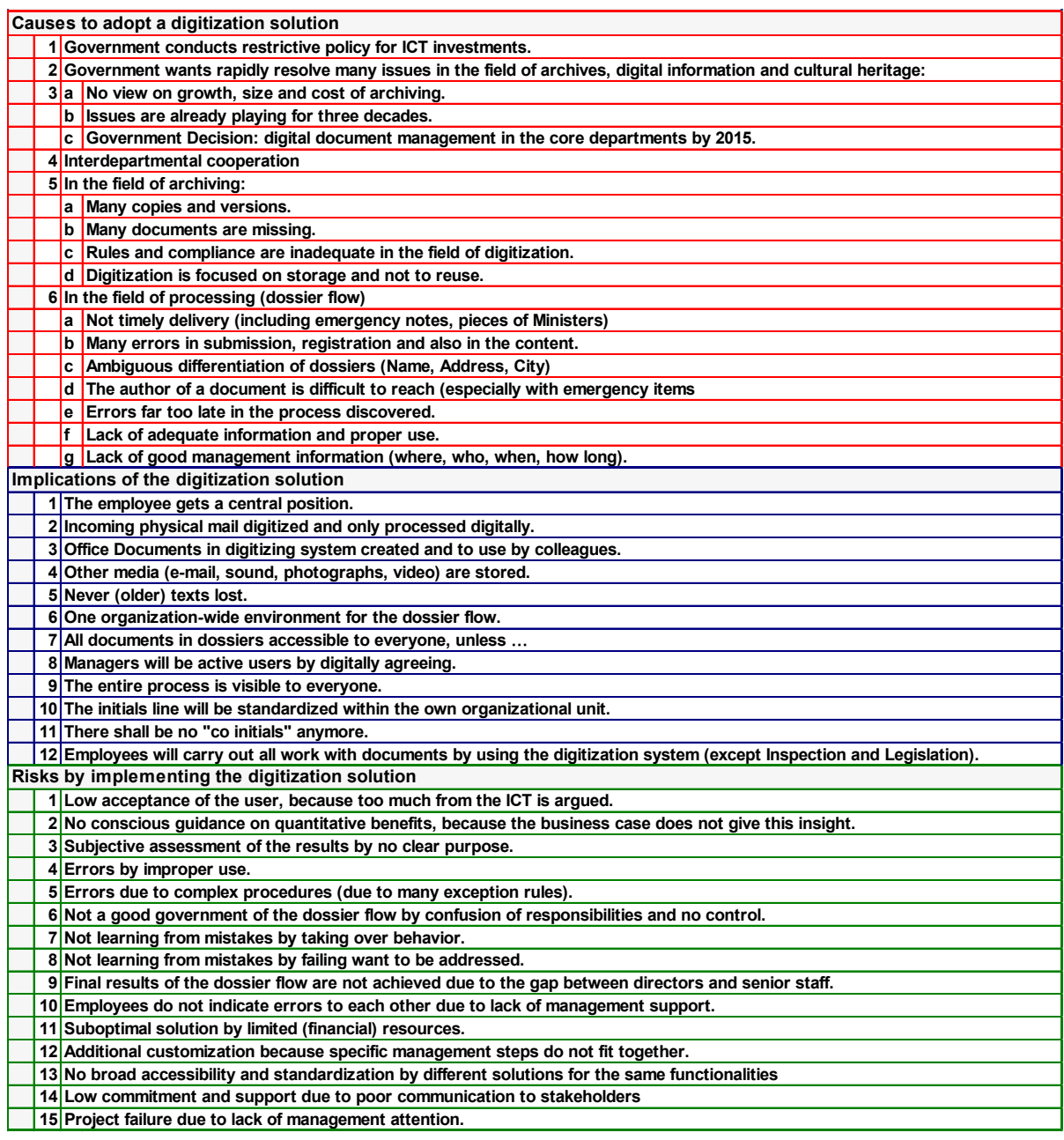

Prior to this workshop, all 22 representatives of the perspectives received a copy of: an overview of all the perspectives and core concepts (see Table 2) and their definitions, an overview of the 219 guiding statements including the perspectives they are connected to, a list of guiding statements on each one perspective (see example Table 3), and a summary of the business issue at hand (see Table 4). In addition, two input forms were issued for the two of the tasks that would need to be performed during the workshop. After the introduction of the business issue by the problem owners, the group of 22 persons was split into four subgroups balanced in proportion to the number of guiding statements and the grouping of perspectives with a strong mutual relevant resemblance. The groups were located in different project rooms and asked to give a plenary wrap up by discussing their three major change initiatives after carrying out the three following tasks: 


\section{Change initiatives based on the analysis of the business issue}

The group was asked to use the causes, implications and risks as identified in Table 4, to list the necessary change initiatives in their perspective.

2. Change initiatives based on the guiding statements

The group was asked to, based on the guiding statements, list those change initiatives that could be carried out to solve/mitigate aspects of the business issue.

3. Prepare for plenary wrap-up

After performing both tasks, each group was asked to identify the three major change initiatives, and prepare a presentation of these initiatives as input to the next plenary part of the workshop.

The workshop resulted in 98 change initiatives of which 15 were prioritized as most important ones. In the last plenary part of the workshop these major change initiatives were presented and all the attendees were offered the opportunity to comment on these. The workshop results were presented as an advisory report to the management of SAE, to decide on the proposed solution and approach.

\section{Experiencies and Insights for Improving GEA}

At the end of the workshops, an evaluation session was organized with the participants of the workshops. This evaluation session resulted in the following shared observations:

1. The participants of the workshops already knew the key principles of this case, but especially the confrontation of these principles with the intended objective of the change program, and the discussions about this were regarded as useful. This provided support, management awareness as well as a more complete picture.

2. An acceleration of the decision-making process and the creation of support at the board level was achieved.

3. A much more holistic approach to the issue compared to the current IT-driven approach. This led to the recognition that much more needed to be changed in the organization than previously assumed.

4. A shorter lead time for obtaining the perspectives and core concepts as a result of the strategy used to first derive guiding statements from policy documents.

5. Saving a lot of processing time regarding the elaboration of the workshop results due to the use of digital forms. This was also experienced as a pleasant way of working by the representatives of the perspectives.

6. The turnaround time of developing the outline of a solution direction, and the choice of the approach to be taken, was reduced to one day using the coherence dashboard.

7. Only a limited number of SAE-employees, for a limited amount of time, (3 hours validation session and 6 hours workshop analyses) were needed in applying GEA.

8. The experience of having 22 representatives of the perspectives meet in a workshop requires timely planning and a convincing modus operandi from the project team, based on a clear problem solving vision and arguments based on added value.

9. The business issue at hand should be positioned at the right management and priority level. This may sound trivial, but especially in the case of business issues that initially 'disguise' themselves as IT-only issues, this is of the utmost importance. 
These observations will serve as input for the further development/improvement of GEA, while also providing relevant starting points for more quantitative follow up research/evaluations.

\section{Conclusion}

In this paper, we discussed a real world case study in Business/IT alignment at the strategic level. The specific business issues addressed in the case were: (1) What are the necessary change initiatives of the introduction of this new system? (2) What are the best choices in terms of solution direction and approach? The coherence dashboard as configured for the Ministry of SAE, illustrated that Business/IT alignment is not only a matter of aligning "the business" and "the IT" aspects of an enterprise. The SAE case indicates that a more refined perspective is called for, in which multiple aspects need to be aligned with the goal of achieving more coherence.

As discussed in the introduction, in the case of the Dutch Ministry of SAE, the GEA method was a given. However, as also indicated, the GEA method is continuously developed further using a design science rhythm. The lessons learned as listed in the previous Section, have already lead to further improvements of the GEA method. In our further research we will, continue to conduct real life case studies, and based on the findings, further elaborate and improve GEA.

\section{References}

1. Balogun, J., Hope Hailey, V., Johnson, G., Scholes, K.: Exploring Strategic Change, 2nd edn. Financial Times Prent.Int (2003) ISBN-13: 9780273683278

2. Greefhorst, D., Proper, H.A.: Architecture Principles - The Cornerstones of Enterprise Architecture. Enterprise Engineering Series. Springer, Berlin (2011), ISBN-13: 9783642202780 , http: //www.springer. com/business+\%26+management/ business+information+systems/book/978-3-642-20278-0

3. Hevner, A.R., March, S.T., Park, J., Ram, S.: Design Science in Information Systems Research. MIS Quarterly 28, 75-106 (2004)

4. Simons, R.: Levers of Control: How Managers Use Control Systems to Drive Strategic Renewal. Harvard Business School Press (1994) ISBN-13: 9780875845593

5. Wagter, R.: Sturen op samenhang op basis van GEA - Permanent en event driven. Van Haren Publishing, Zaltbommel (2009) (in Dutch) ISBN-13: 9789087534066

6. Wagter, R., Nijkamp, G., Proper, H.A.: Overview 1th Phase - General Enterprise Architecturing. White Paper GEA-1, Ordina, Utrecht, The Netherlands (2007) (in Dutch)

7. Yin, R.K.: Case Study Research - Design and Methods, 4th edn. Sage Publications (2009) ISBN-13: 9781412960991 